\title{
Magnetocaloric effect in bulk and nanostructured $\mathrm{Gd}_{3} \mathrm{Fe}_{5} \mathrm{O}_{12}$ materials
}

\author{
M H Phan ${ }^{1}$, M B Morales ${ }^{1}$, C N Chinnasamy ${ }^{2}$, B Latha ${ }^{2}$, V G Harris ${ }^{2}$ and \\ H Srikanth ${ }^{1,3}$ \\ ${ }^{1}$ Department of Physics, University of South Florida, Tampa, FL 33620, USA \\ ${ }^{2}$ Center for Microwave Magnetic Materials and Integrated Circuits (CM3IC) and Department of \\ Electrical and Computer Engineering, Northeastern University, Boston, Massachusetts 02115, USA \\ E-mail: sharihar@cas.usf.edu
}

Received 2 January 2009, in final form 7 April 2009

Published 21 May 2009

Online at stacks.iop.org/JPhysD/42/115007

\begin{abstract}
We report here the magnetocaloric effect (MCE) in bulk and nanostructured gadolinium iron garnets $\left(\mathrm{Gd}_{3} \mathrm{Fe}_{5} \mathrm{O}_{12}\right)$. When compared with the bulk counterpart, the magnitude of the MCE is smaller for nanostructured samples with an average grain size of $50 \mathrm{~nm}$, but increases when the grain size decreases to $35 \mathrm{~nm}$. For the bulk sample, the MCE curves show a broad peak at $35 \mathrm{~K}$; this peak is found to shift to lower temperatures for the nanostructured samples. The origin of the MCE peak for the bulk sample is associated with the intrinsic magnetic frustration and the ferromagnetic ordering of the Gd sublattice below $90 \mathrm{~K}$, while for nanostructured garnets it is additionally ascribed to the surface spin disorder and particle blocking effects. While blocking is detrimental to achieving large MCE, surface spin disorder is found to enhance it under high applied fields.
\end{abstract}

(Some figures in this article are in colour only in the electronic version)

\section{Introduction}

Magnetic refrigeration (MR), based on the magnetocaloric effect (MCE), is a topic of increasing interest, since it provides several important advantages over conventional gas compression refrigeration techniques [1]. These advantages include higher cooling capacity, compact device packaging and environmentally friendly materials. Using paramagnetic salts, such as $\mathrm{Gd}_{2}\left(\mathrm{SO}_{4}\right)_{3} \cdot 8 \mathrm{H}_{2} \mathrm{O}$, the $\mathrm{MR}$ technology has successfully achieved at temperatures in the $\mathrm{mK}$ range. However, room temperature applications have remained out of reach [2-4]. Receiving much interest have been the newly discovered magnetocaloric materials, $\mathrm{Gd}_{5}\left(\mathrm{Si}_{1-x} \mathrm{Ge}_{x}\right)_{4}$ [5], $\operatorname{MnFe}\left(\mathrm{P}_{1-x} \mathrm{As}_{x}\right)$ [6], Ni-Mn-Ga [7], $\mathrm{Mn}\left(\mathrm{As}_{1-x} \mathrm{Sb}_{x}\right)$ [8], $\mathrm{La}\left(\mathrm{Fe}_{x} \mathrm{Si}_{1-x}\right)_{13}$ [9] and manganese oxides of the type $R_{1-x} M_{x} \mathrm{MnO}_{3}$, where $R=\mathrm{La}, \mathrm{Pr}, \mathrm{Nd}$, etc and $M=\mathrm{Ca}$, $\mathrm{Sr}, \mathrm{Ba}, \mathrm{Pb}$, etc [4] that exhibit large MCE around $300 \mathrm{~K}$. These materials are attractive candidate materials for magnetic refrigerants for use in active magnetic refrigerators (AMR) [2-4]. However, it is difficult to make these materials as thin films while maintaining stoichiometry and desirable

\footnotetext{
3 Author to whom any correspondence should be addressed.
}

magnetocaloric properties [10-13]. This is a major drawback as a cooling device for micro electro mechanical systems (MEMS) and nano electro mechanical systems (NEMS) because they require planar or film structures compatible with their geometries [13]. A disadvantage of using these materials is that large MCE can be achieved only over a relatively narrow temperature range in the vicinity of the magnetic phase transition. This causes a major obstacle in achieving high refrigerant capacity (RC) $[2,4]$. A search for new materials that possess both large MCE and high RC is underway.

Nanocrystalline magnetic materials and magnetic nanoparticles may prove superior to their bulk counterparts in that they display reasonably large MCE over a wide temperature range thereby providing enhanced RC [10-13, 14-20]. Nanoparticles in particular are attractive since they may be assembled as thin films through self-assembly. Since magnetic nanoparticles may possess superparamagnetic or magnetic order, depending upon particle size and inter-particle interactions, tailoring of their nanostructure has proven useful in increasing RC [18-20]. Importantly, a larger MCE has been achieved in superparamagnetic nanoparticles than for the more common paramagnetic materials $[10,11]$. These results 


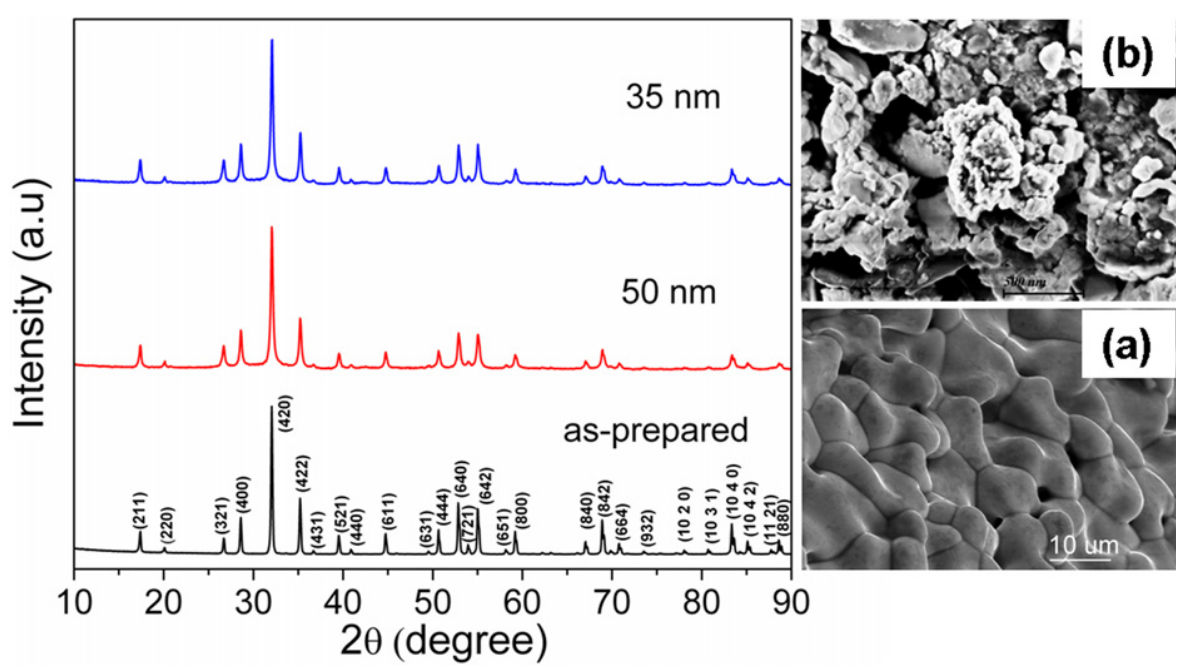

Figure 1. X-ray diffraction patterns and SEM images of $\mathrm{Gd}_{3} \mathrm{Fe}_{5} \mathrm{O}_{12}$ bulk and nanostructured samples. The scanning electron microgrpahs show the surface morphology of the $(a)$ as-prepared and $(b) 35 \mathrm{~h}$ milled $(35 \mathrm{~nm})$ samples.

indicate that nanostructured magnetic materials may prove useful for low-temperature refrigeration applications.

Gadolinium garnets are widely used in applications such as magneto-optical, microwave and electrochemical devices $[21,22]$. They are also promising candidate materials for MR at low temperatures [11,23-25]. The interesting magnetic properties of gadolinium iron garnet $\left(\mathrm{Gd}_{3} \mathrm{Fe}_{5} \mathrm{O}_{12}\right)$, which is the focus of this study, arise mainly from its complex magnetic structure [26,27]. In $\mathrm{Gd}_{3} \mathrm{Fe}_{5} \mathrm{O}_{12}$, two sublattices of ferric ions couple antiferromagnetically via the superexchange interaction through oxygen anions. The formula unit consists of three $\mathrm{Fe}^{3+}$ cations on tetrahedral sites and two $\mathrm{Fe}^{3+}$ cations on octahedral sites [26]. The $\mathrm{Gd}^{3+}$ ions are also antiferromagnetically coupled to the net moment of the $\mathrm{Fe}^{3+}$ ions, but this coupling is weaker than that between $\mathrm{Fe}^{3+}$ ions. Since the $\mathrm{Gd}^{3+}$ ions are disordered at room temperature, the ferrimagnetic properties of the material at high temperature are governed by the moments of the $\mathrm{Fe}^{3+}$ ions [26]. At low temperature, however, the $\mathrm{Gd}^{3+}$ lattice becomes ordered and dominates the magnetic properties of the material due to the larger magnetic moment of $\mathrm{Gd}$ compared with that of $\mathrm{Fe}$ ions. In this temperature range, despite interactions between neighbouring spins, magnetic frustration due to the geometric configuration results in a disordered cooperative paramagnetic state with finite entropy [23]. The presence of geometric magnetic frustration has been demonstrated to be the cause of an enhanced MCE in $\mathrm{Gd}_{3} \mathrm{Ga}_{5} \mathrm{O}_{12}$ (GGG) [28]. In the case of $\mathrm{Gd}_{3} \mathrm{Fe}_{5} \mathrm{O}_{12}$, the magnetic interactions are even more intriguing because of the interplay between the $\mathrm{Fe}$ and $\mathrm{Gd}$ sublattices.

From a magnetic cooling perspective, the study of MCE of $\mathrm{Gd}_{3} \mathrm{Fe}_{5} \mathrm{O}_{12}$ in nanostructured form may be of practical importance. We present here a comparative study of MCE in bulk and ball-milled $\mathrm{Gd}_{3} \mathrm{Fe}_{5} \mathrm{O}_{12}$ with nanoscale grain size. Experimental results indicate that tuning the grain size of $\mathrm{Gd}_{3} \mathrm{Fe}_{5} \mathrm{O}_{12}$ leads to enhancement of the MCE relative to its bulk equivalent.

\section{Experiment}

$\mathrm{Gd}_{3} \mathrm{Fe}_{5} \mathrm{O}_{12}$ particles were synthesized in polycrystalline form by solid state reaction. Starting materials were a mixture of $\mathrm{Gd}_{2} \mathrm{O}_{3}$ and $\alpha-\mathrm{Fe}_{2} \mathrm{O}_{3}$ in the nominal composition ratio $3: 5$. Pure phase $\mathrm{Gd}_{3} \mathrm{Fe}_{5} \mathrm{O}_{12}$ garnet nanopowders were prepared by heating the mixture in an oxygen gas atmosphere three times at temperatures of $1000^{\circ} \mathrm{C}(8 \mathrm{~h}), 1250^{\circ} \mathrm{C}(8 \mathrm{~h})$, and $1290^{\circ} \mathrm{C}(3 \mathrm{~h})$. These conditions are significantly different from conventional solid state processing in which materials are typically annealed at temperatures as high as $1450{ }^{\circ} \mathrm{C}$ for $24 \mathrm{~h}$ or more. Milling of the as-prepared garnet particles was carried out in a controlled atmosphere using a planetary ball mill (Fritsch Pulverisette, P7) with tungsten carbide (WC) balls and vials to reduce the grain size. The vial was sealed in a nitrogen atmosphere using a glove box. The ball to powder weight ratio was $8: 1$. The samples were milled for 10, 20, 35 and $40 \mathrm{~h}$. After selected milling times, a small amount of powder was removed each time from the vial for analysis. The chemical analysis of these samples confirmed that they did not have any contamination from the milling media. Composition analysis using ICP and scanning electron microscope (SEM)EDX confirmed the stoichiometry of Gd:Fe as 3:5. The crystal structure was characterized by $\mathrm{x}$-ray powder diffraction using $\mathrm{Cu} \mathrm{K}_{\alpha}$ radiation $(\lambda=1.5404 \AA$ ) in a Rigaku Ultima III diffractometer. Magnetic measurements were performed using a physical property measurement system (PPMS) from quantum design over the temperature range 5-300 K at applied fields up to $7 \mathrm{~T}$.

\section{Results and discussion}

The XRD patterns and SEM images of the bulk and nanostructured samples are shown in figure 1. For the as-prepared and milled samples, nearly identical patterns corresponding to $\mathrm{Gd}_{3} \mathrm{Fe}_{5} \mathrm{O}_{12}$ (JCPDS-48-0077) are observed. The $\mathrm{x}$-ray line broadening increases with milling time due to the reduction in grain size and possibly increased strain and 


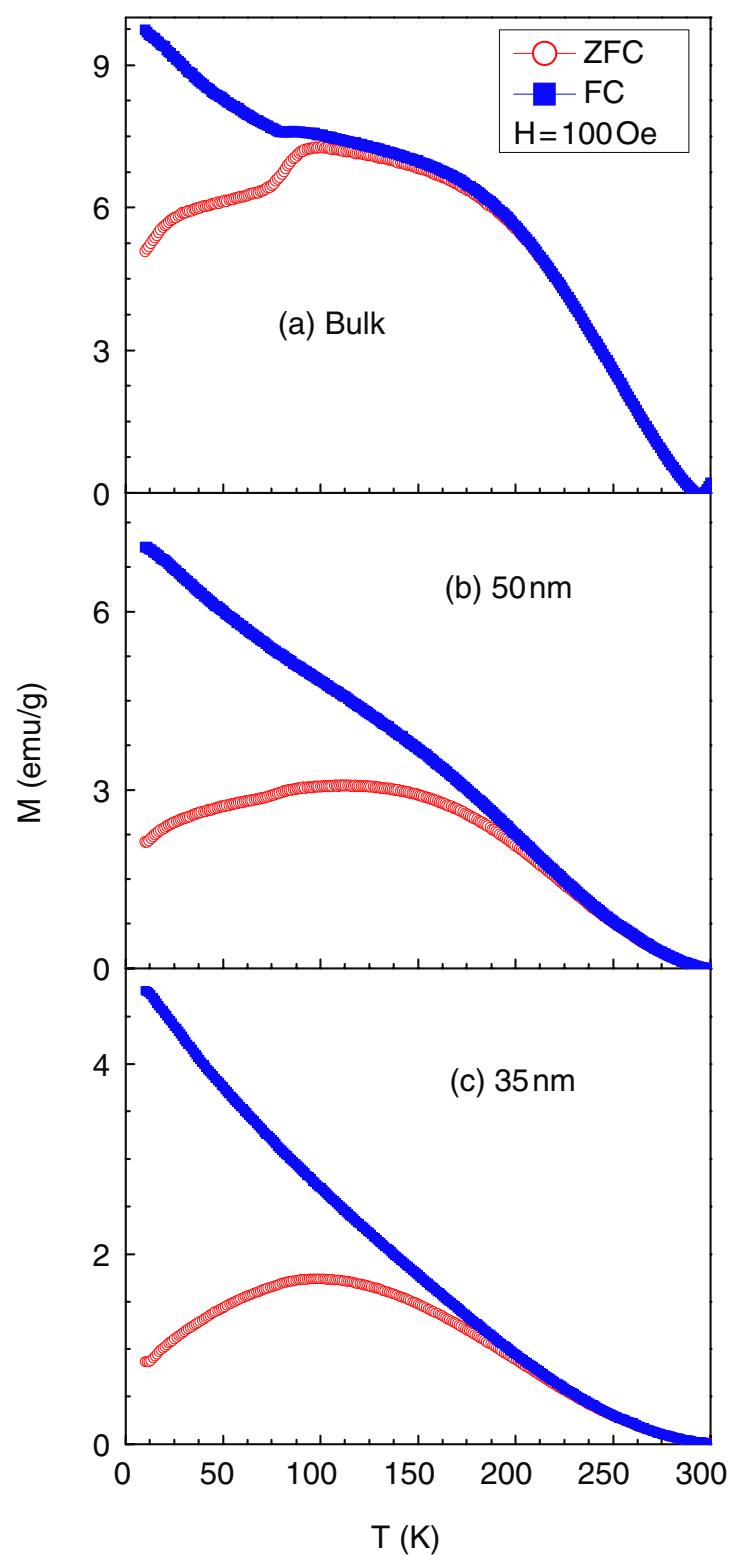

Figure 2. ZFC and FC magnetization data taken at 100 Oe applied field for $(a)$ bulk, (b) $50 \mathrm{~nm}$ and (c) $35 \mathrm{~nm}$ nanostructured $\mathrm{Gd}_{3} \mathrm{Fe}_{5} \mathrm{O}_{12}$.

defects in the lattice. The average grain sizes were determined by applying the Scherrer formula using the full width at half maximum of the (422) diffraction peak with a standard deviation of $12 \%$. All peaks in the diffractograms were indexed on the basis of a garnet unit cell with the lattice parameters determined by fitting the diffraction peak positions using the least-squares reduction method. The surface morphology of the bulk and nanostructured samples is shown in insets $(a)$ and (b), respectively, of figure 1 . The bulk gadolinium iron garnet powder particles are in the micrometre size range, whereas the ball-milled samples show clusters of particles in the nanometre size range. This is typical in high-energy ball-milled samples due to the continuous welding, fracturing and re-welding of the powder particles.

Figures 2(a)-(c) show the temperature dependence of zero-field-cooled (ZFC) and field-cooled (FC) magnetization taken at 100 Oe for the bulk, nanostructured samples with an average grain size of $50 \mathrm{~nm}$ and $35 \mathrm{~nm}$, respectively. Henceforth, we will refer to these three samples as bulk, $50 \mathrm{~nm}$ and $35 \mathrm{~nm}$ samples without repeatedly using the term 'nanostructured' to describe the latter two samples. It can be observed from figure 2(a) that for the bulk sample, the ZFC curve exhibits two cusps at $\sim 115$ and $\sim 35 \mathrm{~K}$ that are associated with glass transitions. Ac susceptibility measurements (not shown here) have been used to independently confirm the glassy nature of the system. Noticeably, there is a sharp increase in the FC magnetization below $\sim 90 \mathrm{~K}$, which coincides with the magnetic ordering temperature of the Gd sublattice [24]. Therefore, the bulk $\mathrm{Gd}_{3} \mathrm{Fe}_{5} \mathrm{O}_{12}$ system undergoes two different glass transitions with the magnetic moments of $\mathrm{Gd}$ being disordered at high temperature $(T>$ $90 \mathrm{~K}$ ) and ordered at low temperature $(T<90 \mathrm{~K})$. The features associated with glass characteristics in the bulk sample is less pronounced in the nanostructured samples and are largely suppressed with decreasing grain size (see figures $2(b)$ and $(c))$. Ac susceptibility measurements on the 50 and $35 \mathrm{~nm}$ samples have also revealed two frequency-dependent susceptibility peaks although the overall glass signatures are largely suppressed in these samples relative to the bulk sample. It is worth noting from figures $2(b)$ and $(c)$ that the ZFC curves exhibit blocking-superparamagnetic behaviour with the ZFC peak temperatures of $\sim 125 \mathrm{~K}$ and $\sim 100 \mathrm{~K}$ for the $50 \mathrm{~nm}$ and $35 \mathrm{~nm}$ samples, respectively. This is consistent with the general expectation that samples with smaller average nanocrystallite size should have a lower blocking temperature [29]. This also indicates that for the case of the nanostructured samples, the blocking effect is present and becomes dominant as the grain size is reduced. A detailed study of the glass dynamics and competing effects of blocking and spin frustration in these nanostructured systems is beyond the scope of this paper and will be reported in a future publication.

In this paper, our main focus is on exploring the MCE in bulk and nanostructured $\mathrm{Gd}_{3} \mathrm{Fe}_{5} \mathrm{O}_{12}$ materials. To evaluate the MCE of the samples, the isothermal magnetization curves were collected at different fixed temperatures ranging from 5 to $300 \mathrm{~K}$ and a family of such curves is displayed in figures $3(a)-(c)$. As one can clearly see from figure $3(a)$, for the bulk sample the $M-H$ curves show typical saturation consistent with mean-field ferromagnetic behaviour and this is in good agreement with the previous report by McMichael et al [25]. However, the nanostructured samples exhibit nonsaturating $M-H$ curves with gradual curvature suggestive of superparamagnetic behaviour (see figures $3(b)$ and $(c)$ ). As the average grain size decreases from 50 to $35 \mathrm{~nm}$, the shape of the $M-H$ curve changes consistently with the superparamagnetic response. The $M-H$ data in figure 3 are also consistent with the ZFC magnetization data in figure 2 . From a magnetocaloric material perspective, it is worth mentioning that the difference in magnetization becomes significantly larger at lower temperatures for the bulk and $35 \mathrm{~nm}$ samples (see figures $3(a)$ and $(c)$ ) than for the $50 \mathrm{~nm}$ sample (see figure $3(b))$. This implies that for these samples, the large MCE (i.e. the large magnetic entropy change) and its peak would occur at low temperatures, and that the magnitude of the MCE should be larger for the bulk and $35 \mathrm{~nm}$ samples. 

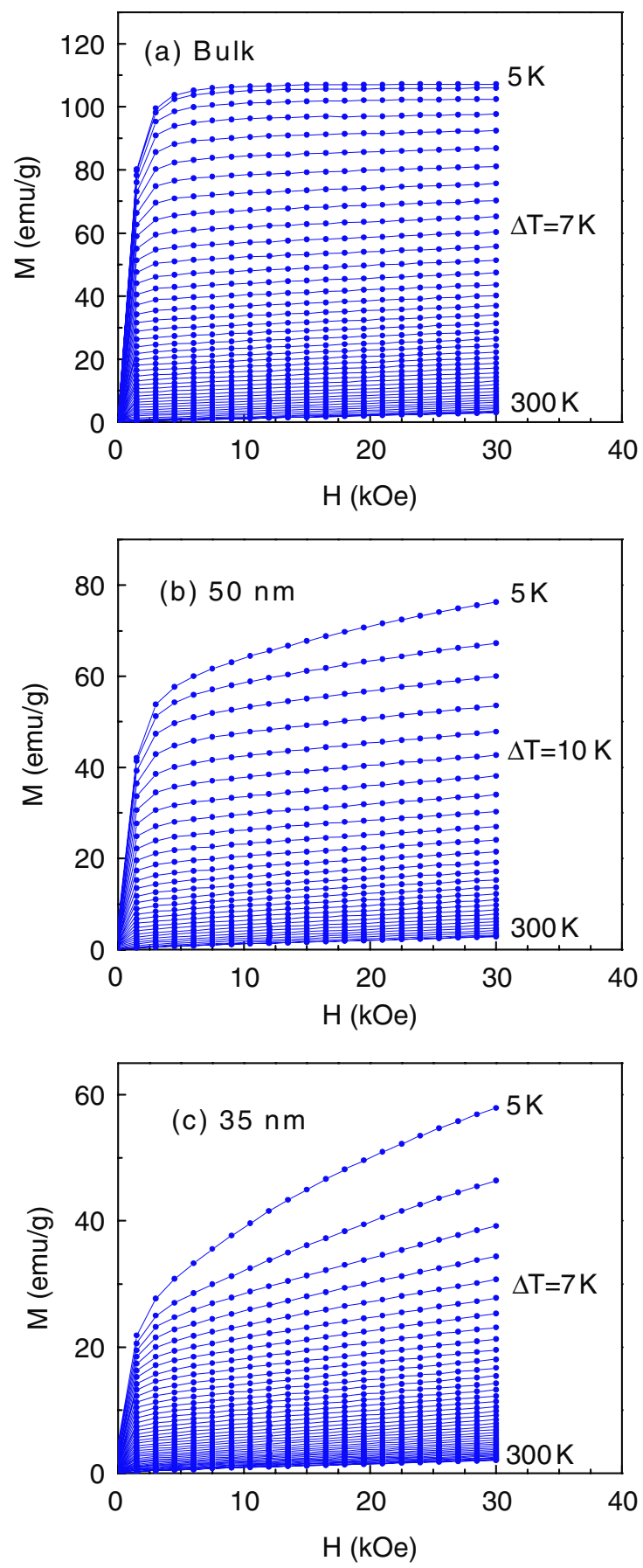

Figure 3. Isothermal magnetization curves taken at different fixed temperatures between 5 and $300 \mathrm{~K}$ for $(a)$ bulk, (b) $50 \mathrm{~nm}$ and (c) $35 \mathrm{~nm}$ nanostructured samples.

The magnetic entropy change $\Delta S_{\mathrm{M}}$ has been calculated from the $M-H$ curves (figure 3 ) using the Maxwell relation [1],

$$
\Delta S_{\mathrm{M}}=\mu_{0} \int_{0}^{H_{\max }}\left(\frac{\partial M}{\partial T}\right)_{H} \mathrm{~d} H,
$$

where $M$ is the magnetization, $H$ is the magnetic field and $T$ is the temperature. The temperature dependence of $-\Delta S_{\mathrm{M}}$ at different applied fields for the bulk, $50 \mathrm{~nm}$ and $35 \mathrm{~nm}$ samples is plotted in figures $4(a)-(c)$, respectively. It can be observed that for the bulk sample, the $-\Delta S_{\mathrm{M}}(T)$ curves show a broad
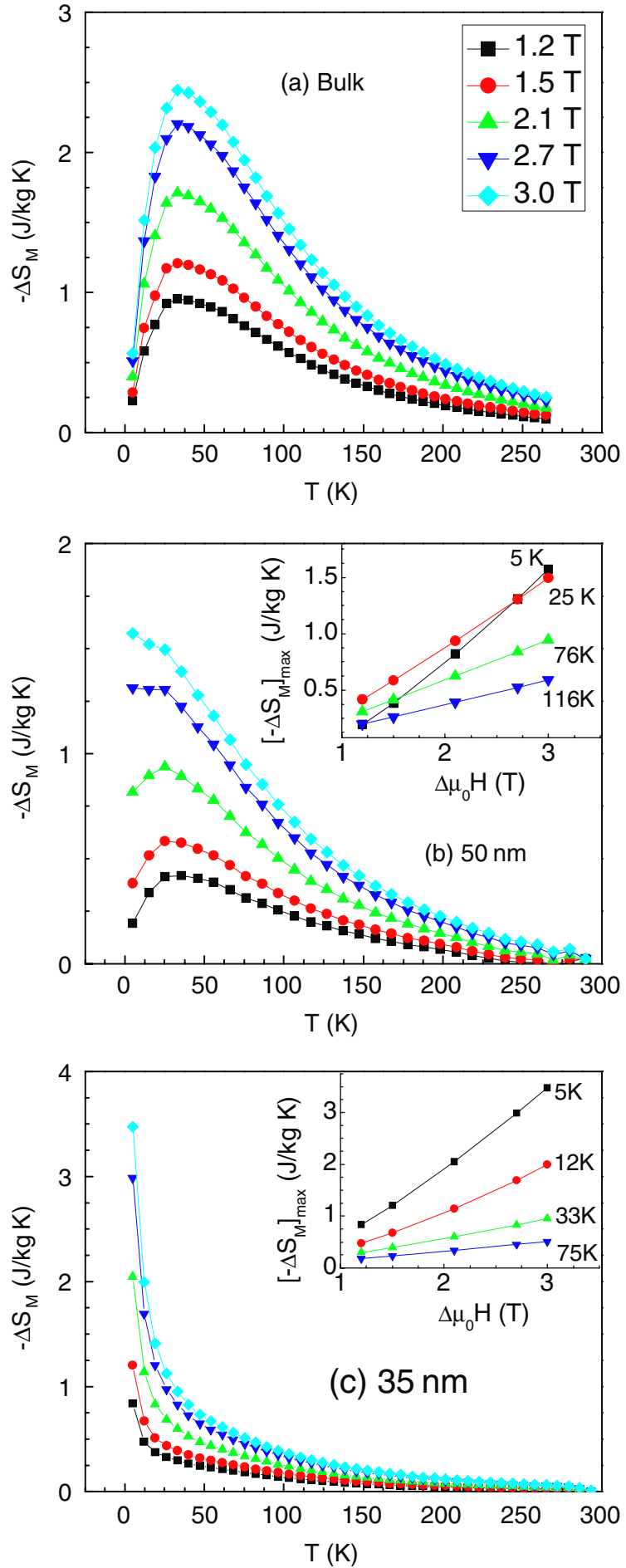

Figure 4. Temperature dependence of magnetic entropy change $-\Delta S_{\mathrm{M}}$ at different applied fields up to $3 \mathrm{~T}$ for $(a)$ bulk, $(b) 50 \mathrm{~nm}$ and (c) $35 \mathrm{~nm}$ samples. In figure 4(b), the inset shows the magnetic field dependence of the maximum magnetic entropy change $\left(-\Delta S_{\mathrm{M}}^{\max }\right)$ for the $50 \mathrm{~nm}$ sample. In figure 4(c), the inset shows the magnetic field dependence of the maximum magnetic entropy change $\left(-\Delta S_{\mathrm{M}}^{\max }\right)$ for the $35 \mathrm{~nm}$ sample.

peak at $\sim 35 \mathrm{~K}$ (see figure $4(a)$ ) and this peak shifts to a lower temperature $(\sim 25 \mathrm{~K})$ for the case of the $50 \mathrm{~nm}$ sample (see figure $4(b))$. It is noted that while the $-\Delta S_{\mathrm{M}}(T)$ peak for the bulk sample is almost independent of the applied magnetic 


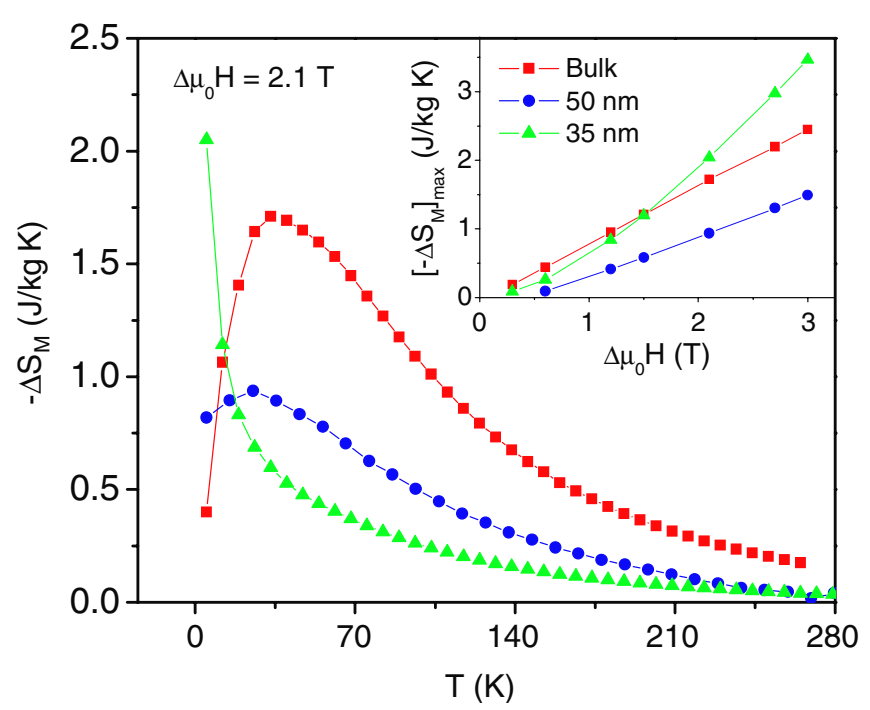

Figure 5. The magnetic entropy change $\left(-\Delta S_{\mathrm{M}}\right)$ as a function of temperature for $\Delta \mu_{0} H=2.1 \mathrm{~T}$ for the bulk, 50 and $35 \mathrm{~nm}$ samples. The inset shows the magnetic field dependence of the maximum magnetic entropy change $\left(-\Delta S_{\mathrm{M}}^{\max }\right.$ ) for the bulk (at $\left.35 \mathrm{~K}\right), 35 \mathrm{~nm}$ (at $5 \mathrm{~K}$ ) and $50 \mathrm{~nm}$ (at $25 \mathrm{~K}$ ) samples.

field, the one for the $50 \mathrm{~nm}$ sample tends to shift towards a lower temperature as the applied magnetic field is increased. This trend is consistent with our observation that the maximum magnetic entropy change $\left(-\Delta S_{\mathrm{M}}^{\max }\right)$ of the $50 \mathrm{~nm}$ sample at $5 \mathrm{~K}$ increases abruptly with applied magnetic field and becomes larger than the one at $25 \mathrm{~K}$ (where the MCE peak is centred) for a change in magnetic field of $3 \mathrm{~T}$ (see inset of figure $4(b)$ ). For the $35 \mathrm{~nm}$ sample, the peak of $-\Delta S_{\mathrm{M}}(T)$ shifts to even lower temperatures and only the sharp rise is detected in the temperature range 5-300 K (see figure 4(c)). For this sample, a large MCE is achieved and the largest value of $-\Delta S_{\mathrm{M}}^{\max }$ is achieved at $5 \mathrm{~K}$ (see inset of figure $4(c)$ ). For a better comparison, we display in figure 5 the $-\Delta S_{\mathrm{M}}(T)$ data for the bulk, 50 and $35 \mathrm{~nm}$ samples at the same applied magnetic field of $2.1 \mathrm{~T}$. The magnetic field dependences of $-\Delta S_{\mathrm{M}}^{\max }$ for the bulk sample at $35 \mathrm{~K}$, for the $50 \mathrm{~nm}$ sample at $25 \mathrm{~K}$, and for the $35 \mathrm{~nm}$ sample at $5 \mathrm{~K}$ are also included in the inset of figure 5 . From the magnetic cooling perspective, it is very interesting to see, as in the inset of figure 5, that reducing the average grain size to $50 \mathrm{~nm}$ results in a decrease in $-\Delta S_{\mathrm{M}}$, but a further reduction to $35 \mathrm{~nm}$ increases $-\Delta S_{\mathrm{M}}$. As compared with the bulk counterpart, the $-\Delta S_{\mathrm{M}}$ magnitude for the $35 \mathrm{~nm}$ sample is larger for $\Delta \mu_{0} H>1.5 \mathrm{~T}$. Corresponding to an increase in the applied magnetic field of $3 \mathrm{~T}$, the $-\Delta S_{\mathrm{M}}$ is found to be $\sim 3.47 \mathrm{~J} \mathrm{~kg}^{-1} \mathrm{~K}^{-1}$ for the $35 \mathrm{~nm}$ sample, while it is about $2.45 \mathrm{~J} \mathrm{~kg}^{-1} \mathrm{~K}^{-1}$ for the bulk material.

To put our results in perspective, we summarize in table 1 the values of $-\Delta S_{\mathrm{M}}^{\max }$ of the present $\mathrm{Gd}_{3} \mathrm{Fe}_{5} \mathrm{O}_{12}$ materials and some other cryogenic magnetic refrigerant materials from the literature including previous work from our own group. It can be seen from table 1 that for $\Delta \mu_{0} H=1 \mathrm{~T}$, the $-\Delta S_{\mathrm{M}}^{\max }$ value of bulk $\mathrm{Gd}_{3} \mathrm{Fe}_{5} \mathrm{O}_{12}$ in the present case $\left(0.78 \mathrm{~J} \mathrm{~kg}^{-1} \mathrm{~K}^{-1}\right)$ is larger compared with that of the bulk $\mathrm{Gd}_{3} \mathrm{Fe}_{5} \mathrm{O}_{12}$ reported previously by McMichael et al $\left(0.45 \mathrm{~J} \mathrm{~kg}^{-1} \mathrm{~K}^{-1}\right)$ [25]. We have evaluated the relative cooling power $(\mathrm{RCP})$ of the present bulk $\mathrm{Gd}_{3} \mathrm{Fe}_{5} \mathrm{O}_{12}$ sample using the same method as described in [4] and obtain a relatively large value of $288 \mathrm{~J} \mathrm{~kg}^{-1}$ for $\Delta \mu_{0} H=3 \mathrm{~T}$. However, it would not be possible to get a reliable quantitative estimate of the RCP for the nanostructured $\mathrm{Gd}_{3} \mathrm{Fe}_{5} \mathrm{O}_{12}$ samples because they do not possess a well-defined $-\Delta S_{\mathrm{M}}(T)$ peak down to the lowest temperature accessible to us $(4.2 \mathrm{~K})$ but instead show the $-\Delta S_{\mathrm{M}}(T)$ steadily increasing with decreasing temperature. Thus, to keep the comparisons meaningful, only the magnitude of $-\Delta S_{\mathrm{M}}$ of these samples are evaluated and summarized in table 1 . For all the compared nanostructured samples, it is interesting to note that for $\Delta \mu_{0} H=1 \mathrm{~T}$ the $-\Delta S_{\mathrm{M}}^{\max }$ value of the $35 \mathrm{~nm} \mathrm{Gd}_{3} \mathrm{Fe}_{5} \mathrm{O}_{12}$ is larger than that of $\mathrm{NiFe}_{2} \mathrm{O}_{4}$ but smaller than those of $\mathrm{Co}$ and $\mathrm{Co}_{\text {core }} \mathrm{Ag}_{\text {shell }}$ nanoparticles. However, for $\Delta \mu_{0} H=3 \mathrm{~T}$ the $-\Delta S_{\mathrm{M}}^{\max }$ value of the $35 \mathrm{~nm}$ sample is much larger than that of all the other samples. Since the $-\Delta S_{\mathrm{M}}$ of the $35 \mathrm{~nm}$ sample increases rapidly as the temperature is lowered, this material can be a potential candidate for MR at temperatures below $\sim 10 \mathrm{~K}$.

Now, let us discuss the possible origin of the $-\Delta S_{\mathrm{M}}(T)$ peak and the $-\Delta S_{\mathrm{M}}^{\max }(H)$ dependence in the bulk and nanostructured $\mathrm{Gd}_{3} \mathrm{Fe}_{5} \mathrm{O}_{12}$ samples. We recall that for conventional magnetocaloric materials, the $-\Delta S_{\mathrm{M}}(T)$ peak is located near the magnetic ordering transition temperature [1-4]. Thus, one may expect a similar feature in the nanoparticle samples in the vicinity of the superparamagnetic to blocking transition. However, experimental studies on a number of magnetic nanoparticle systems have shown that the magnitude of the $-\Delta S_{\mathrm{M}}$ is relatively small and only shows a broad feature over a wide temperature region around the blocking transition $[15,16]$. While the small magnitude of $-\Delta S_{\mathrm{M}}$ is not desirable, its nearly constant value over a large temperature range may prove useful in enhancing the $\mathrm{RC}$ $[13,15,16]$. For the case of the nanostructured $\mathrm{Gd}_{3} \mathrm{Fe}_{5} \mathrm{O}_{12}$ samples, the $-\Delta S_{\mathrm{M}}(T)$ peak is located at low temperatures (figure 4) much below their blocking temperatures (figure 2). This apparently excludes the blocking transition as the origin of the $-\Delta S_{\mathrm{M}}(T)$ main peak in these samples.

As shown previously by Bohigas et al [30], the peak of $-\Delta S_{\mathrm{M}}(T)$ observed in $\mathrm{Tb}_{0.5} \mathrm{Y}_{0.5} \mathrm{Al}_{2}$ was associated with the spin-glass transition temperature. In this case, the bulk $\mathrm{Gd}_{3} \mathrm{Fe}_{5} \mathrm{O}_{12}$ sample exhibits two glass-like peaks at $\sim 115$ and $\sim 35 \mathrm{~K}$ leading to a similar expectation that this system should also possess two peaks of $-\Delta S_{\mathrm{M}}(T)$ at these temperatures. However, only a broad peak of $-\Delta S_{\mathrm{M}}(T)$ is observed around $35 \mathrm{~K}$, which is the second glass transition temperature. This difference can be explained by considering the fact that in $\mathrm{Gd}_{3} \mathrm{Fe}_{5} \mathrm{O}_{12}$ the magnetic moments of $\mathrm{Gd}$ are disordered at $T>90 \mathrm{~K}$ and become ordered at $T<90 \mathrm{~K}$. As a result, the MCE in this material at low temperatures below $90 \mathrm{~K}$ is likely governed by the ferromagnetic ordering of the Gd moments [23], and a broad peak of $-\Delta S_{\mathrm{M}}(T)$ around $35 \mathrm{~K}$ is the result of the much larger value of $-\Delta S_{\mathrm{M}}$ around $35 \mathrm{~K}$ compared with that around $115 \mathrm{~K}$. For the $50 \mathrm{~nm}$ sample, the shift of the $-\Delta S_{\mathrm{M}}(T)$ peak to $25 \mathrm{~K}$ is consistent with the ac susceptibility results confirming that the glassy state is largely suppressed in this nanostructured sample relative to its bulk counterpart. For the $35 \mathrm{~nm}$ sample, the blocking effect appears to be dominant 
Table 1. Maximum magnetic entropy change, $\left|\Delta S_{\mathrm{M}}^{\max }\right|$, occurring at the peak temperature, $T_{\mathrm{P}}$, for $\Delta \mu_{0} H=1 \mathrm{~T}$ and $3 \mathrm{~T}$, for several magnetic refrigerant candidate materials.

\begin{tabular}{lllll}
\hline Material & $\Delta \mu_{0} H(\mathrm{~T})$ & $T_{\mathrm{P}}(\mathrm{K})$ & $\left|\Delta S_{\mathrm{M}}^{\max }\right|\left(\mathrm{J} \mathrm{kg}^{-1} \mathrm{~K}^{-1}\right)$ & Reference \\
\hline $\mathrm{Gd}_{3} \mathrm{Ga}_{5} \mathrm{O}_{12}$ (bulk) & 1 & 10 & 1.50 & {$[25]$} \\
$\mathrm{Gd}_{3} \mathrm{Ga}_{2.5} \mathrm{Fe}_{2.5} \mathrm{O}_{12}$ (bulk) & 1 & 10 & 2.25 & {$[25]$} \\
$\mathrm{Gd}_{3} \mathrm{Fe}_{5} \mathrm{O}_{12}$ (bulk) & 1 & 40 & 0.45 & {$[25]$} \\
$\mathrm{Gd}_{3} \mathrm{Fe}_{5} \mathrm{O}_{12}$ (bulk) & 1 & 35 & 0.78 & Present \\
$\mathrm{Gd}_{3} \mathrm{Fe}_{5} \mathrm{O}_{12}(50 \mathrm{~nm})$ & 1 & 25 & 0.31 & Present \\
$\mathrm{Gd}_{3} \mathrm{Fe}_{5} \mathrm{O}_{12}(35 \mathrm{~nm})$ & 1 & 5 & 0.67 & Present \\
$\mathrm{NiFe}_{2} \mathrm{O}_{4}(6-15 \mathrm{~nm})$ & 1 & 5 & 0.18 & {$[16]$} \\
$\mathrm{Co}(50 \mathrm{~nm})$ & 1 & 15 & 1.00 & {$[15]$} \\
$\mathrm{Co}_{\text {core }} \mathrm{Ag}_{\text {shell }}(40-28 \mathrm{~nm})$ & 1 & 20 & 0.82 & {$[15]$} \\
$\mathrm{Gd}_{3} \mathrm{Fe}_{5} \mathrm{O}_{12}($ bulk) & 3 & 35 & 2.45 & Present \\
$\mathrm{Gd}_{3} \mathrm{Fe}_{5} \mathrm{O}_{12}(50 \mathrm{~nm})$ & 3 & 25 & 1.49 & Present \\
$\mathrm{Gd}_{3} \mathrm{Fe}_{5} \mathrm{O}_{12}(35 \mathrm{~nm})$ & 3 & 5 & 3.47 & Present \\
$\mathrm{NiFe}_{2} \mathrm{O}_{4}(6-15 \mathrm{~nm})$ & 3 & 5 & 1.15 & {$[16]$} \\
$\mathrm{Co}_{50}(5 \mathrm{~nm})$ & 3 & 15 & 2.30 & {$[15]$} \\
$\mathrm{Co}_{\text {core }} \mathrm{Ag}_{\text {shell }}(40-28 \mathrm{~nm})$ & 3 & 20 & 2.30 & \\
\hline
\end{tabular}

over the intrinsic spin frustration effect and the increase in $-\Delta S_{\mathrm{M}}$ with decreasing temperature is consequently observed.

Furthermore, recent studies have shown that reducing grain size enhances surface spin disorder, thus inducing a spin-glass-like freezing transition, and the prominent MCE peak is observed in the vicinity of this transition $[15,16]$. As reported earlier in [16], the $-\Delta S_{\mathrm{M}}(T)$ curves of ballmilled nanocrystalline $\mathrm{ZnFe}_{2} \mathrm{O}_{4}$ clearly exhibited a peak at the freezing temperature associated with disordered surface spins. In this case, we believe that the decrease in grain size leads to the misalignment of surface spins thus affecting the $-\Delta S_{\mathrm{M}}(T)$ behaviour (i.e. the peak position and magnitude of $-\Delta S_{\mathrm{M}}(T)$ ) in the nanostructured $\mathrm{Gd}_{3} \mathrm{Fe}_{5} \mathrm{O}_{12}$ samples. For the $50 \mathrm{~nm}$ sample, the contribution to $-\Delta S_{\mathrm{M}}$ from the surface spin disorder becomes significant at sufficiently high applied magnetic fields $\left(\Delta \mu_{0} H>2 \mathrm{~T}\right)$, as can be seen in figure $4(b)$ and its inset. In contrast, for the $35 \mathrm{~nm}$ sample, the disorder of surface spins is largely due to the reduced grain size. Therefore, the shift of the $-\Delta S_{\mathrm{M}}(T)$ peak to lower temperature and the strong increase in magnitude of $-\Delta S_{\mathrm{M}}$ with decreasing temperature for the $35 \mathrm{~nm}$ sample (see figure $4(c)$ and its inset) can also be attributed to the strong effect of surface spin disorder. As compared with the bulk counterpart, the reduction in $-\Delta S_{\mathrm{M}}^{\max }$ for the $50 \mathrm{~nm}$ sample is likely associated with the decrease in the saturation magnetization (see figure 6) whereas the enhancement in $-\Delta S_{\mathrm{M}}^{\max }$ for the $35 \mathrm{~nm}$ sample for $\Delta \mu_{0} H>1.5 \mathrm{~T}$ is due to the strong effect of the applied magnetic field on the disordered surface spins. Nonsaturation of the magnetization and the increase in its slope with decreasing particle size in the nanostructured samples (see figure 6 and its inset) also confirm the influence of surface spin disorder in these samples.

To fully understand the variation of $-\Delta S_{\mathrm{M}}(T)$ in the nanostructured $\mathrm{Gd}_{3} \mathrm{Fe}_{5} \mathrm{O}_{12}$ samples, we note that the change in the overall magnetization is influenced by various factors, such as the Zeeman energy, due to the applied field, thermal energy $k_{\mathrm{B}} T$, anisotropy energy and inter-particle interactions [19]. If one of these energies (for example, the thermal agitation energy) changes due to variation in temperature, then the balance among other contributions is broken causing a change

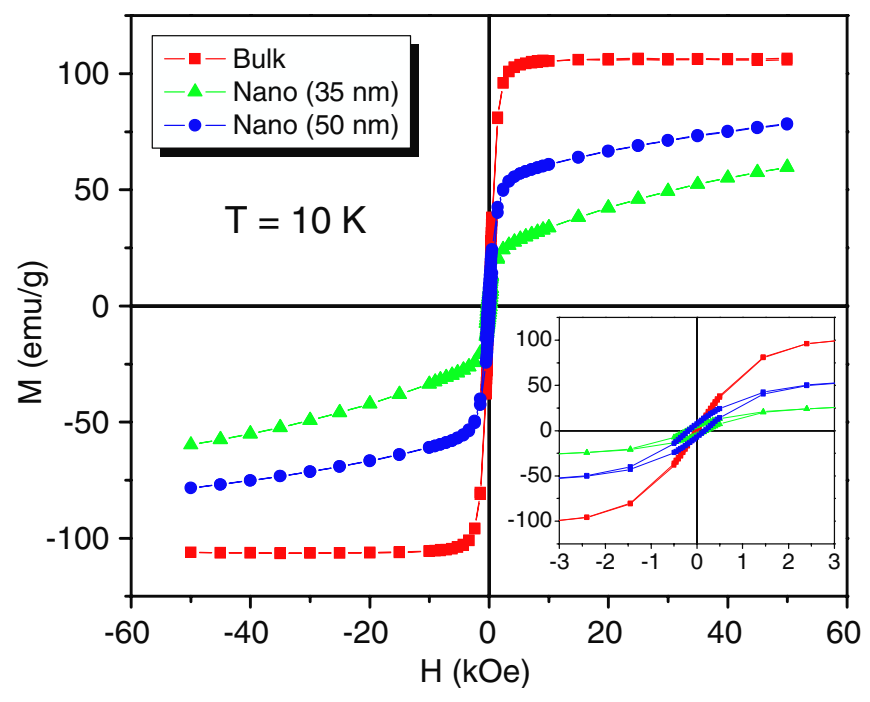

Figure 6. Magnetic loops taken at $10 \mathrm{~K}$ for the bulk, 35 and $50 \mathrm{~nm}$ samples.

in the overall magnetization. As the external magnetic field is applied, the magnetization of the individual nanocrystalline particles is determined by the sum of the projections of each particle's moment along the direction of the external magnetic field. At low temperatures, thermal fluctuations are negligible and the Zeeman energy dominates. Consequently, particle moments can rotate freely and align along the direction of the applied magnetic field increasing the overall magnetization of the system. In addition, in the low-temperature range, the magnetic moment density of $\mathrm{Gd}_{3} \mathrm{Fe}_{5} \mathrm{O}_{12}$ is large due to the fact that $\mathrm{Gd}$ has an atomic moment of $7.2 \mu_{\mathrm{B}}$ and orders at these temperatures $[23,25]$. This explains why the low temperature $-\Delta S_{\mathrm{M}}$ of the nanostructured $\mathrm{Gd}_{3} \mathrm{Fe}_{5} \mathrm{O}_{12}$ is large and increases rapidly with decreasing temperature. A similar trend has also been observed in high-spin paramagnetic rare-earth fluorites [29] and superparamagnetic nanoparticles [19], and agrees fully with theoretical predictions of the temperature-dependent $-\Delta S_{\mathrm{M}}$ for superparamagnetic nanoparticles and nanoclusters [31-33]. It has been shown that for superparamagnetic nanoparticles with higher energy barriers (i.e. high blocking 
temperature), the blocked state is detrimental to achieving large MCE [19]. Thus, in this case, a smaller $-\Delta S_{\mathrm{M}}$ value is expected for the $50 \mathrm{~nm}$ sample than for the $35 \mathrm{~nm}$ sample.

\section{Conclusions}

The MCE has been studied in bulk and nanostructured $\mathrm{Gd}_{3} \mathrm{Fe}_{5} \mathrm{O}_{12}$ materials. When compared with the bulk counterpart, the magnitude of MCE is smaller for the $50 \mathrm{~nm}$ samples, but increases when the grain size decreases to $35 \mathrm{~nm}$. For the bulk sample, the MCE curves show a peak near $\sim 35 \mathrm{~K}$; this peak is found to shift to lower temperatures for the nanostructured samples. The origin of the MCE peak for the bulk sample is associated with the intrinsic magnetic frustration effect and the sharp change in the magnetic ordering of the Gd sublattice, while for nanostructured garnets it is additionally ascribed to the surface spin disorder and blocking effects. While blocking is detrimental to achieving large MCE, surface spin disorder is found to enhance it under high applied fields. These nanostructured garnets are potential candidate materials for cryogenic MR applications.

\section{Acknowledgments}

Work at USF was supported by the DOE BES Physical Behaviour of Materials Programme through grant number DE-FG02-07ER46438. HS also acknowledges support from USAMRMC through grant number W81XWH-07-1-0708. Northeastern University researchers were supported, in part, by the Office of Naval Research (N00014-05-10349) and the National Science Foundation (DMR 0400676).

\section{References}

[1] Tishin A M and Spichkin Y I 2003 The Magnetocaloric Effect and its Applications (Bristol: Institute of Physics Publishing)

[2] Pecharsky V K, Gschneidner K A and Tsokol A O 2005 Rep. Prog. Phys. 681479

[3] Bruck E 2005 J. Phys. D: Appl. Phys. 38 R381

[4] Phan M H and Yu S C 2007 J. Magn. Magn. Mater. 308325

[5] Pecharsky V K and Gschneidner K A 1997 Phys. Rev. Lett. 784494

[6] Tegus Q, Bruck E, Buschow K H and de Boer F R 2002 Nature 415150

[7] Hu F X, Shen B G, Sun J R and Wu G H 2001 Phys. Rev. B 64132412

[8] Wada H and Tanabe Y 2001 Appl. Phys. Lett. 793302
[9] Fujieda S, Fujita A and Fukamichi K 2002 Appl. Phys. Lett. 811276

[10] McMichael R D, Shull R D, Swartzendruber L J, Bennett L H and Watson R E 1992 J. Magn. Magn. Mater. 11129

[11] Provenzano V, Li J, King T, Canavan E, Shirron P, DiPirro M and Shull R D 2003 J. Magn. Magn. Mater. 266185

[12] Srikanth H and Gass J 2005 Rev. Adv. Mater. Sci. 10398

[13] Poddar P, Gass J, Rebar D J, Srinath S, Srikanth H, Morrison S A and Carpenter E E 2006 J. Magn. Magn. Mater. 307227

[14] Zhang X X, Wei H L, Zhang Z Q and Zhang L 2001 Phys. Rev. Lett. 87157203

[15] Poddar P, Srinath S, Gass J, Prasad B L V and Srikanth H 2007 J. Phys. Chem. C 11114060

[16] Gass J, Srikanth H, Kislov N, Srinivasan S S and Emirov Y 2008 J. Appl. Phys. 103 07B309

[17] Yamamoto T A, Tanaka M, Nakayama T, Nishimaki K, Nakagawa T, Katsura M and Nihara K, 2000 Japan. J. Appl. Phys. 394761

[18] Kinoshita T, Seino S, Maruyama H, Otome Y, Okitsu K, Nakayama T, Niihara K, Nakagawa T and Yamamoto T A, 2004 J. Alloys Compounds $\mathbf{3 6 5} 281$

[19] Ma S, Li WF, Li D, Xiong D K, Sun N K, Geng D Y, Liu W and Zhang Z D, 2007 Phys. Rev. B 76144404

[20] Franco V, Pirota K R, Prida V M, Neto A M J C, Conde A, Knobel M, Hernando B and Vazquez M 2008 Phys. Rev. B 77104434

[21] Grasset F, Mornet S, Etourneau J, Haneda H and Bobet J L, 2003 J. Alloys Compounds 359330

[22] Kharton V V, Shaula A L, Naumovich E N, Vyshatko N P, Marozau I P, Viskup A P and Marques F M B 2003 J. Electrochem. Soc. $150 \mathrm{~J} 33$

[23] Belov K N, Talalaeva E V, Chernikova L A, Ivanovskii V I and Kudryavtseva T V 1969 J. Exp. Theor. Phys. Lett. 9416

[24] Levitin R Z, Snegirev V V, Kopylov A V, Lagutin A S and Gerber A, 1997 J. Magn. Magn. Mater. 170223

[25] McMichael R D, Ritter J J and Shull R D, 1993 J. Appl. Phys. 736946

[26] Rodic D, Tomkowicz Z, Novakovic L, Szytula A and Lj Napijalo M, 1990 Solid State Commun. 73243

[27] Waerenborgh J C, Rojas D P, Shaula A L, Kharton V V and Marques F M B, 2000 Mater. Lett. 583432

[28] Zhitomirsky M E, 2003 Phys. Rev. B 67104421

[29] Goya G F, Berquó T S, Fonseca F C and Morales M P 2003 J. Appl. Phys. 943520

[30] Bohigas X, Tejada J, Torres F, Arnaudas J I, Joven E and Moral A 2002 Appl. Phys. Lett. 812427

[31] Fernandez A, Bohigas X, Tejada J, Sulyanova E A, Irina I. Buchinskaya and Sobolev B P 2007 Mater. Chem. Phys. 10562

[32] Baldomir D, Rivas J, Serantes D, Pereiro M, Arias J E, Bujan,-Nunez M C and C. Vazquez-Vazquez $2007 \mathrm{~J}$. Non-Cryst. Solids 353790

[33] Skomski R, Binek C, Mukherjee T, Sahoo S and Sellmyer D J 2008 J. Appl. Phys. 103 07B329 